\title{
Oral Misoprostol for Induction of Labor
}

\author{
Shikha Seth, Arun Nagrath, Neeru Goel \\ Dept. of Obs /Gyn \\ Rural Institute of Medical Sciences \& Research, \\ Saifai, Etawah, Uttar Pradesh, India
}

\begin{abstract}
Aim: To assess the efficacy of Misoprostol $50 \mu \mathrm{gms}$ orally for induction of labour in third trimester over conventional oxytocin infusion.

Methods: Design: A prospective cohort study done at U.P.RIMS \& R Saifai. Study population: 112 antenatal women requiring induction for any medical or obstetrical reason in third trimester of pregnancy, who were randomly selected into two groups; 60 women received $50 \mu \mathrm{gms}$ of Misoprostol orally with water at 4 hourly intervals to a max. Of $200 \mu \mathrm{gms}$ while 52 received oxytocin infusion by titration. Parameters: onset of uterine contractions, fetal heart rate and change in Bishop Score, Induction to delivery interval (IDI), mode of delivery and outcomes were analyzed.
\end{abstract}

Results: Mean Bishop Score was 2.4 \pm 1.3 , which increased to $4.5 \pm 1.48$ after the $1^{\text {st }}$ dose of Misoprostol. Vaginal delivery occurred in $78.4 \%$ compared to $76.9 \%$ in oxytocin group and Mean induction to delivery interval (IDI) was significantly better in misoprostol group (20.95hrs) compared to (29.75hrs) in oxytocin

Conclusion: $50 \mu \mathrm{gms}$ dose orally was found to be an effective and safe method for third trimester induction with live babies with proper monitoring.

Key words: Misoprostol, induction of labor, rupture of membranes, oxytocin augmentation.

\section{Introduction}

Induction of labour is an important aspect of obstetrics practice. It is needed in cases where continuation of pregnancy may adversely affect the fetus, mother or both and after 40 weeks to prevent complications of post maturity. Since a decade oxytocin has been used for this purpose, which requires infusion, titration, and frequent monitoring often taking significant time especially with unripe cervix that poses a problem. Prostaglandin's (PG's) are another compounds used for induction of labour and has a better outcome as it ripens the cervix along with stimulating myometrial contractility. PG's commonly used are PGE-2, dinoprostone intracervical gel and PGE-1 Misoprostol, which has gained recent popularity.

Misoprostol overcomes most of drawbacks of Oxytocin. It can be given orally, vaginally, rectally, and sublingually and mother remains mobile until she goes in active labour. This study is done to evaluate the efficacy of misoprostol $50 \mu$ gms orally for induction of labour in third trimester of pregnancy.

\section{Methods}

112 antenatal women requiring induction for any medical or obstetrical reason in third trimester of pregnancy, 28 weeks onwards admitted in wards of U.P. RIMS \& R Saifai, over the period of six months were taken into the study. Women with malpresentation, multiple pregnancy, cephalo-pelvic disproportion, previous caesarean section, placenta previa $>$ type II, good size baby (i.e. $\geq 4 \mathrm{Kgs}$ weight by ultrasonogaphy), severe renal and hepatic diseases, or having any contraindication to prostaglandin's such as glaucoma, asthma, heart disease were excluded from the study. Women in third trimester of pregnancy with singleton gestation in cephalic presentation, with Bishop $\leq 4$ on admission, reassuring cardio-tocography in case of live baby, and having no other obstetrical contraindication for vaginal delivery were selected for induction.

Informed written consent was taken from all subjects requiring induction for one or another reason. All were subjected to detailed history, systemic and obstetrical examination having investigated to rule out the high 
risk factors. Selected cases were divided in two groups randomly by chit system. Women in group I had conventional titrated oxytocin infusion for induction while in group II were given $50 \mu$ gms of misoprostol orally with water and dose was repeated at 4 hourly intervals after assessing uterine contractions, fetal heart rate and change in Bishop Score. Maximum dose of misoprostol fixed to $200 \mu \mathrm{gms}$ (4doses) or $40 \mathrm{mIU} / \mathrm{min}$ for oxytocin infusion.

Patients with inadequate contraction pattern after total dose of $200 \mu \mathrm{gms}$ of misoprostol. If uterine contractions are not settled even after maximum $200 \mu$ gms dose, it was termed failed misoprostol induction and they were subjected for oxytocin augmentation starting with $2.5 \mathrm{mIU} / \mathrm{min}$. Artificial rupture of membranes (ARM) was done at active phase ( $4-5 \mathrm{cms}$ cervical dilatation) of labour. Women were kept on strict fetal heart rate monitoring, done by intermittent full one minute auscultation every $30 \mathrm{~min}$ in latent phase, $15 \mathrm{~min}$ in active phase and every $5 \mathrm{~min}$. in second stage of labour. If any irregularity, bradycardia or tachycardia was noted, they were subjected to Cardiotocography (CTG). Induction protocol was stopped immediately in cases of hypertonus or hyperstimulation syndrome or fetal distress whenever irregular heart rate pattern, Non-reassuring fetal heart rate pattern were detected in CTG or thick meconium stained liquor was observed on spontaneous or after ARM.

Results were evaluated in form of change in Bishop Score, onset of uterine contractions, successful vaginal deliveries, induction to delivery interval (IDI), reason for caesarian section.

\section{Results}

Among 112 antenatal women selected for induction of labour, 52 were ultimately selected in group I in Oxytocin induction protocol while 60 in Misoprostol group II. Mean age, weight, parity, gestational age like parameters were comparable in two groups. (Table 1)

\section{Table 1. Demographic profile of cases in both groups.}

\begin{tabular}{lllll}
\hline S.N. & parameters & & Oxytocin Gr. & Misoprostol Gr. \\
\hline 1. & Age (years) & Mean \pm SD & $23.4 \pm 4.8$ & $26.2 \pm 5.3$ \\
2. & parity & Nullipara & 28 & 34 \\
& & Multigravida & 24 & 26 \\
& & Mean \pm SD & $59.2 \pm 4.4$ & $57.3 \pm 5.2$ \\
3. & Weight (kg) & & & \\
4. & Gestational age & $>37$ weeks & 32 & 38 \\
& Term & $<37$ weeks & 20 & 22 \\
5. & Preterem & Mean \pm SD & $2.8 \pm 1.2$ & $2.4 \pm 1.3$ \\
6. & Membrane status & Intact & 34 & 35 \\
& & Ruptured & 18 & 25 \\
\hline
\end{tabular}

Table 2. Indications for induction of labour

\begin{tabular}{rlcc}
\hline S.N. & Indications & $\begin{array}{c}\text { Oxytocin Gr. } \\
\mathbf{N}=\mathbf{5 2}(\%)\end{array}$ & $\begin{array}{c}\text { Misoprostol Gr. } \\
\mathbf{N}=\mathbf{6 0}(\%)\end{array}$ \\
\hline 1. & PROM & $18(34.6 \%)$ & $25(41.7 \%)$ \\
2. & Post dated pregnancy & $16(30.8 \%)$ & $15(25 \%)$ \\
3. & IUFD & $7(13.4 \%)$ & $8(13.3 \%)$ \\
4. & Pre-Eclampsia & $2(3.8 \%)$ & $5(8.3 \%)$ \\
5. & Congenital anomalies & $8(15.4 \%)$ & $5(8.3 \%)$ \\
6. & IUGR / oligohydroamnios & $1(1.9 \%)$ & $2(3.4 \%)$ \\
\hline 7. & Total & $52(100 \%)$ & $60(100 \%)$ \\
\hline
\end{tabular}


Table 3. Indication of caesarean in both the groups

\begin{tabular}{|c|c|c|c|c|c|c|}
\hline \multirow[t]{2}{*}{ S. $\mathbf{N}$. } & \multirow{2}{*}{$\begin{array}{l}\text { Indications } \\
\text { For } \\
\text { Caesarean }\end{array}$} & \multicolumn{2}{|c|}{ Oxytocin Gr. } & \multicolumn{2}{|c|}{ Misoprostol Gr. } & \multirow[t]{2}{*}{$P$-value } \\
\hline & & $\begin{array}{l}\text { Ruptured } \\
\text { membrane } \\
(\mathrm{n}=18) \%\end{array}$ & $\begin{array}{l}\text { Intact } \\
\text { membrane } \\
(\mathrm{n}=34)\end{array}$ & $\begin{array}{l}\text { Ruptured } \\
\text { membrane } \\
(\mathrm{n}=25)\end{array}$ & $\begin{array}{l}\text { Intact } \\
\text { membrane } \\
(\mathrm{n}=35)\end{array}$ & \\
\hline 1. & Non Reassuring CST & $\begin{array}{l}1 \\
5.5 \%\end{array}$ & $\begin{array}{l}2 \\
(5.9 \%)\end{array}$ & $\begin{array}{l}2 \\
(12 \%)\end{array}$ & $\begin{array}{l}2 \\
(5.7 \%)\end{array}$ & 0.28 \\
\hline 2. & Meconium stain liquor & $\begin{array}{l}1 \\
(5.5 \%)\end{array}$ & $\begin{array}{l}1 \\
(2.9 \%)\end{array}$ & $\begin{array}{l}3 \\
(12 \%)\end{array}$ & $\begin{array}{l}2 \\
(5.7 \%)\end{array}$ & 0.19 \\
\hline 3. & Failed Induction & $\begin{array}{l}3 \# \\
(22.2 \%)\end{array}$ & $\begin{array}{l}1 \# \\
(2.9 \%)\end{array}$ & $\begin{array}{l}1 \\
(4 \%)\end{array}$ & $\begin{array}{l}1 \\
(2.8 \%)\end{array}$ & $\begin{array}{l}0.02 \\
\text { significant }\end{array}$ \\
\hline 4. & Non Progress of labour & $\begin{array}{l}2 \\
(11.1 \%)\end{array}$ & $\begin{array}{l}1 \\
(2.9 \%)\end{array}$ & $\begin{array}{l}1 \\
(4 \%)\end{array}$ & $\begin{array}{l}1 \\
(2.8 \%)\end{array}$ & 0.22 \\
\hline 5. & Total & 12 & & 13 & & 0.33 \\
\hline
\end{tabular}

\# Significant $(\mathrm{p}$ - value $<0.05$ )

Table 4. Induction outcomes in two groups

\begin{tabular}{cllll}
\hline Parameters & $\begin{array}{l}\text { Mean Induction delivery } \\
\text { interval (hrs) } \\
\text { Mean + SD }\end{array}$ & $\begin{array}{l}\text { Vaginal delivery } \\
\text { No. (\%) }\end{array}$ & $\begin{array}{l}\text { Hypersensitivity } \\
\text { / hyperstimulation }\end{array}$ & $\begin{array}{l}\text { Oxytocin } \\
\text { acceleration } \\
\text { after 5 doses }\end{array}$ \\
\hline Oxytocin Group & & 11 & None & - \\
Ruptured & $26.8 \pm 9.5$ & $(61.1 \%)$ & None & - \\
N=18 & & 29 & & \\
Intact & $32.7 \pm 6.5$ & $(85.3 \%)$ & & 2 \\
N=34 & & 18 & & \\
Misoprostol Gr. & & $(72 \%)$ & & \\
Ruptured & $19.8 \pm 6.8$ & 29 & none & \\
N=25 & & $(82.8 \%)$ & & \\
Intact & $22.1 \pm 7.12$ & & & \\
N=35 & & &
\end{tabular}

Most common indication for induction was prolonged ruptured membranes, present in 43 (38.39\%) followed by post-datism $(27.67 \%)$. Table 2

Cases that were induced at gestation age of less than 37 weeks (preterm) were $42(37.5 \%)$. Mean Bishop Score was $2.8 \pm 1.2$ in Oxytocin group, while $2.4 \pm 1.3$ in Misoprostol group at time of induction, which increased to $4.5 \pm 1.48$ four hours after the $1^{\text {st }}$ dose of $50 \mu \mathrm{gm}$ oral misoprostol, while in group I it increased only to $3.8 \pm 1.3$. Mean dose of misoprostol required was $152 \mu \mathrm{gms}$ and six cases required oxytocin augmentation after complete $200 \mu \mathrm{gm}$. dose. Vaginal delivery rate was almost comparable in the two groups but in ruptured membrane cases higher percentage required Caesarian.(Table 3, 4). Induction failure rate was significantly high in oxytocin receiving ruptured membrane group $(\mathrm{p}=0.02)$.

Mean induction to delivery interval (IDI) was significantly better in misoprostol group (20.95hrs) compared to $(29.75 \mathrm{hrs})$ in oxytocin. Tachysystole 
was observed in one case, of misoprostol, along with meconium staining of liquor, no other contraction abnormality was detected. Nausea vomiting was commonest side effect found in $22(20 \%)$ of cases, diarrhea occurred in two misoprostol cases postnatal. Among 84 live born neonates 15 babies required NNU admission, ten had Apgar score less than 7 at birth and two had meconium aspiration syndrome which recovered subsequently.

\section{Discussion}

Prostaglandins are being used since last two decades in obstetrics practice. Misoprostol the synthetic analogue of PGE1 was initially used for NSAID induced gastric ulcers. It was found that pregnant patient taking this drug had abortion. After many trials it has been approved for first trimester medical abortion but not yet for induction labor by FDA. Many studies have been done over misoprostol given at different doses by different routes, standard protocol is yet to be developed. It is a less expensive water-soluble drug which is stable at room temperature being easily absorbed orally. It undergoes rapid de-esterification to form 'Misoprostol acid' which is an active metabolite' Action peaks at 30 minutes and terminal half-life is 40 minutes. After which concentration drops down.

Windrim R. et al ${ }^{2}$ used $50 \mu$ gms oral misoprostol for induction at four hourly intervals and found that mean induction to delivery interval (IDI) was $926 \pm 521$ minutes. They compared this with their established protocol of using either PG gel or artificial rupture of membranes (ARM) followed by oxytocin infusion and found no difference in maternal or fetal outcome.

Shetty $A$. et $a l^{\mathcal{B}}$ compared $50 \mu \mathrm{gms}$ oral misoprostol induction with oxytocin in PROM cases and stated that $72 \%$ cases in study group delivered within 24 hours with no significant difference in outcome. Our results with oral misoprostol are quite similar with these studies having $72 \%$ vaginal delivery rate and mean IDI of 19.8.1 \pm 6.8 hours.

Hall $R$. et al $^{4}$ compared $100 \mu \mathrm{gms}$ oral with $25 \mu \mathrm{gms}$ vaginal route of misoprostol and stated that oral regimen to be as safe and effective as vaginal. IDI with oral dosage was $1074+488$ minutes and reported caesarean rate of $17 \%$ almost comparable with our $21.6 \%$ with $50 \mu \mathrm{gms}$ dose.

Maximum daily dose of misoprostol was $200 \mu \mathrm{gms}$. In oral route drug concentration peaks rapidly in 30 minutes and drops fast in 40-60minutes so the drug does not accumulates and side effects are much less (Zeiman $M$ et al $)^{5}$. A high plasma peak level makes the cervix ripen before the contraction settles; a better part of oral administration. In vaginal route peak levels are not so high and plateau after that (half life by vaginal route is 4.5 hours.) so there is much chance of accumulation even after drug being repeated at four hourly intervals. Prolonged sustained effect causes contractile abnormalities. One disadvantage of oral route is drug once taken can not be removed while in vaginal route it can be washed off with saline if hyper stimulation develops.

A study by Deborah $A$. wing et al ${ }^{6}$ using $25 \mu \mathrm{gms}$ misoprostol vaginally 3 hourly reports $17.4 \%$ incidence of tachysystole and $5.8 \%$ hyperstimulation. S.W.

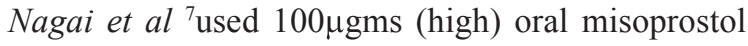
four hourly, $32.5 \%$ cases developed tachysystole but hyperstimulation was not observed in any case even at such high dose. Nausea and vomiting cannot be definitively attributed to misoprostol as it had been also due to rapidly dilating cervix.

\section{Conclusion}

Misoprostol has the dual action of cervical ripening and stimulation of uterine contractions simultaneously, hence this drug given in doses of 50micrograms orally was found to be an effective, safe and acceptable method for third trimester induction of labour even with live fetus. Compared to oxytocin it was found to be better beginning with its cheaper price, easy oral administration, allowing mobility and on the top of its rapid action.

\section{References}

1. Li XM, Wan J, Xu CF et al. Misoprostol in labor induction in term pregnancy: a meta-analysis. Chin Med J (ENGL) 2004; 117:449-452.

2. Windrim R, Bennett K, Mundle W, Young DC. Oral administration of misoprostol for labor induction: a randomized controlled trial. Obstet Gynecol 1997; 899: 392-397.

3. Shetty A, Stewart K, Stewart G, Rice P, Danielian $\mathrm{P}$ Templeton A. active management for term prelabour rupture of membranes with oral misoprostol. BJOG 2002; 109(12): 1354-1358.

4. Hall R, Duarte-Gardea M, Harlass F. Oral versus vaginal misoprostol for labor induction. Obstet Gynecol 2002 Jun; 99(6): 1044-1048.

5. Zeiman M, Fong SK, Benowitz NL, Banskter D, Darney PD. Absorption kinetics of misoprostol with oral or vaginal administration. Obstet Gynecol 1997; 90: 88-91.

6. Deborah A. wing, Rahall A, Jones MM, Goodwin TM, Paul RH. Misoprostol: An effective agent for cervical ripening and labor induction. Am J Obstet Gynecol 1995; 172: 1811-1816.

7. S.W. Nagai, Chan YM, Lam SW, Lao TT. Labour characteristics and uterine activity: Misoprostol compared with oxytocin in women at term with pre-labour rupture of membranes. BJOG 2000; 107 (2): 222-227. 